\title{
CFD ANALYSIS OF CALANDRIA BASED NUCLEAR REACTOR: PART-I. MODELING \& ANALYSIS OF MODERATOR
}

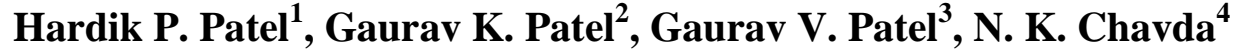 \\ ${ }^{1}$ UG Student, Dept. of Mechanical Engg, A.D.Patel Institute of Technology, New V.V.Nagar, Gujarat, India \\ ${ }^{2} U G$ Student, Dept. of Mechanical Engg, A.D.Patel Institute of Technology, New V.V.Nagar, Gujarat, India \\ ${ }^{3}$ Assistant Professor, Dept. of Mechanical Engg, A.D.Patel Institute of Technology, New V.V.Nagar, Gujarat, India \\ ${ }^{4}$ Associate Professor, Dept. of Mechanical Engg, A.D.Patel Institute of Technology, New V.V. Nagar, Gujarat, India
}

\begin{abstract}
Nuclear power is a cost-effective supply-side technology for mitigating climate change and can make a substantial contribution to climate protection. A nuclear power plant is a thermal power station in which the primary heat source is a nuclear reactor. In the present work, study of Temperature distribution of Moderator in Calandria of Nuclear Reactor is carried out. The study includes the complete understanding of the design of Calandria and how moderators carry out the heat from calandria. Various factors playing vital role in the designing of Calandria and their effect on the Moderator are observed with the help of simulation. The Temperature distribution is validated with actual working conditions.
\end{abstract}

Keywords: CANDU Reactor, Calandria, Moderator, CFD Analysis, temperature distribution

\section{INTRODUCTION}

Nuclear Energy is the energy of the particles inside an atomic nucleus [1]. The Nuclear particles are bound together by the strong nuclear force. In fact the nucleus is the densest the hardest part on an atom which is a result of this strong nuclear force that binds the particles within. Changes occurring in the structure of the nuclei of atoms is called nuclear reaction and the energy created in a nuclear reaction is called nuclear or atomic energy. Nuclear reactions of importance in energy production are Radioactivity Fusion and Fission. Nuclear fusion and nuclear fission are two different types of energy-releasing reactions in which energy is released from high-powered atomic bonds between the particles within the nucleus. The main difference between these two processes is that fission is the splitting of an atom into two or more smaller ones while fusion is the fusing of two or more smaller atoms into a larger one. A nuclear chain reaction occurs when one nuclear reaction causes an average of one or more nuclear reactions, thus leading to a selfpropagating series of reactions. A nuclear reactor is a device to initiate and control a sustained nuclear chain reaction.

A nuclear power plant is a thermal power station in which the heat source is a nuclear reactor. As is typical in all conventional thermal power stations the heat is used to generate steam which drives a steam turbine connected to a generator which produces electricity.

\section{CALANDRIA}

All nuclear reactors operate on the same basic principle, although there are different kinds of nuclear reactors in use throughout the world. A nuclear power station design in Canada, known as the CANadian Deuterium Uranium (CANDU) reactor, uses a calandria reactor core which is based on the use of heavy water, or deuterium, and natural uranium fuel.

The core of a CANDU reactor is contained in a large, horizontal, cylindrical tank called a "calandria" which contains the heavy water moderator. Several hundred fuel channels run from one end of the calandria to the other. Each channel has two concentric tubes.

As shown in Fig 1, the tubes in red color show calandria tubes, in which fuel bundles are kept. The rods in brown color show control rod using for absorption of neutrons as per requirement. Horizontal blue pipes are inlet of moderator and vertical blue pipes are outlet. Calandria is isolated at both ends using end shield due to radioactivity. The whole assembly of coolant tubes and control rods is submerged in moderator. Moderator is a medium that reduce the speed of first neutrons, thereby turning them into thermal neutrons capable of sustaining a nuclear chain reaction. Commonly used moderators include regular water, solid graphite and heavy water.

The fuel, in the form of bundles of rods containing uranium pellets, is inserted into the pressure tubes by remotely operated fuelling machines, which can function while the reactor is operating [2]. 


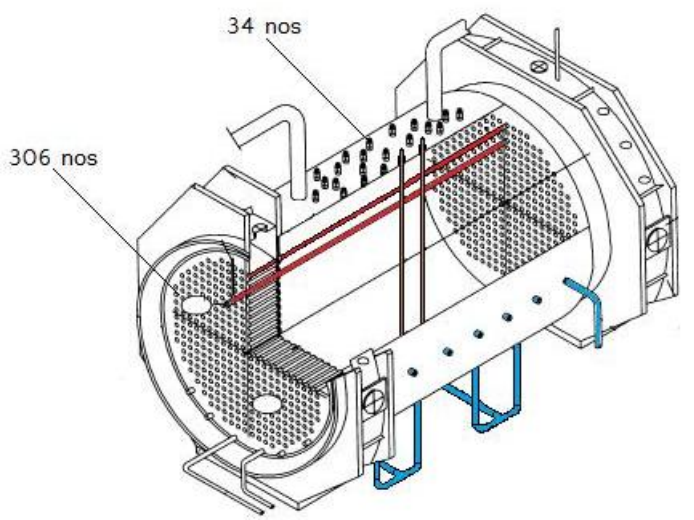

Fig1: Sectional View of Calandria

\section{RESEARCH METHODOLOGY}

The general procedure for solving any 2-D or 3-D simulation problem in ANSYS WORKBENCH is mainly divided into 4 steps.

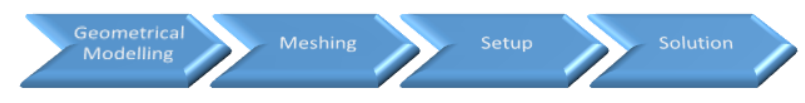

Fig2: Procedure for simulation

\subsection{Geometrical Modelling}

The Calandria model discussed in the present paper is used for a 220 MW capacity Nuclear Power Plant.

The dimensions of geometry are given in following table:

Table1: Geometrical features

\begin{tabular}{|l|l|l|}
\hline $\begin{array}{l}\text { Sr. } \\
\text { No }\end{array}$ & Parameter & $\begin{array}{l}\text { Dimensions } \\
\text { (in mm) }\end{array}$ \\
\hline 1. & Calandria diameter & 6046 \\
\hline 2. & Calandria length & 4159 \\
\hline 3. & Coolant channel diameter & 107.7 \\
\hline 4. & Center-center distance & 228.6 \\
\hline 5. & Moderator inlet/outlet pipe diameter & 200 \\
\hline 6. & Control rod diameter & 70 \\
\hline
\end{tabular}

The basic geometry is created by using Creo-Parametric Software. The geometry is shown in Fig 3. given below.
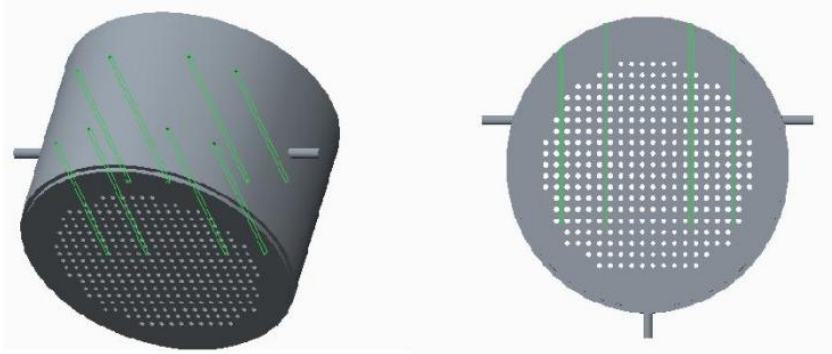

\subsection{CFD Modelling}

Since, the given design is symmetrical the inner volume has been halved to reduce the computational time and expenditure as shown in the Fig 4.

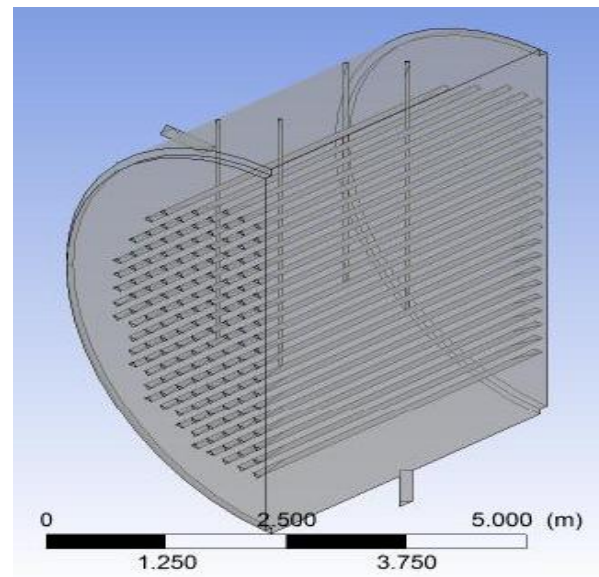

Fig4: Inner Volume of Calandria

\subsection{Meshing}

In order to analyze fluid flows, flow domains are split into smaller subdomains which are made up of geometric primitives like hexahedral and tetrahedral in 3D and quadrilaterals and triangles in 2D. The subdomains are often called elements or cells, and the collection of all elements or cells is called a mesh or grid. The process of obtaining an appropriate mesh (or grid) is termed mesh generation (or grid generation), and has long been considered a bottleneck in the analysis process due to the lack of a fully automatic mesh generation procedure [5].

The table given below provides the meshing specifications.

Table2: Mesh Specifications

\begin{tabular}{|l|l|l|}
\hline $\begin{array}{l}\text { Sr. } \\
\text { No }\end{array}$ & Particulars & Significance \\
\hline 1. & Meshing Method & Unmapped \\
\hline 2. & Type of elements & Tetrahedrons \\
\hline 3. & No: of Nodes & 174449 \\
\hline 4. & No: of Elements & 964571 \\
\hline
\end{tabular}

The figure given below shows the meshed volume of the Calandria as per the meshing specifications.

Fig3: Model of Calandria 


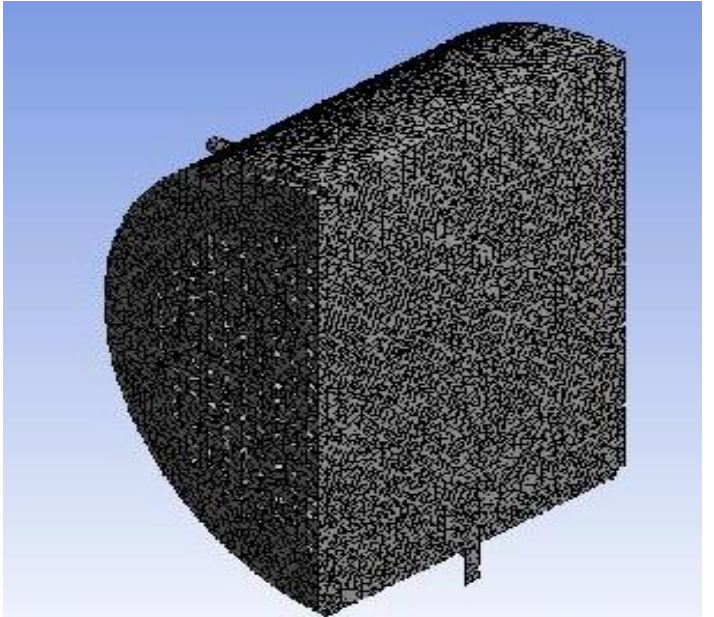

Fig5: Meshed Image of Calandria

\subsection{Setup}

\subsubsection{Assumptions}

In order to perform CFD analysis of the Calandria various assumptions need to be carried out as follows:

1. Heat generated by 306 tubes are assumed as uniform throughout the length.

2. Heat generated by all the tubes are assumed same throughout the calandria.

3. Neutron flux density is assumed to be uniform throughout the calandria.

\subsubsection{Properties of Fluid and Solid}

The description of fluid as well as solid used for simulation are as per the tables given below.

\section{Table3: Fluid Properties}

\begin{tabular}{|l|l|l|}
\hline $\begin{array}{l}\text { Sr. } \\
\text { No }\end{array}$ & Property & Value \\
\hline 1. & Fluid & Heavy Water \\
\hline 2. & Density & $1104.36 \mathrm{Kg} / \mathrm{m}^{3}$ \\
\hline 3. & Specific Heat & $1.6907 \mathrm{~J} / \mathrm{Kg} \mathrm{K}$ \\
\hline 4. & Thermal Conductivity & $0.595 \mathrm{~W} / \mathrm{m} \mathrm{K}$ \\
\hline 5. & Viscosity & $1095 \mathrm{Kg} / \mathrm{m} \mathrm{s}$ \\
\hline & & \\
\hline
\end{tabular}

\begin{tabular}{|l|l|l|}
\multicolumn{3}{|c}{ Table4: Solid Properties } \\
\begin{tabular}{|l|l|l|} 
Sr. \\
No
\end{tabular} & Property & Value \\
\hline 1. & Material & Zircolay 2 \\
\hline 2. & Density & $6560 \mathrm{Kg} / \mathrm{m}^{3}$ \\
\hline 3. & Specific Heat & $0.285 \mathrm{~J} / \mathrm{Kg} \mathrm{K}$ \\
\hline 4. & Thermal Conductivity & $21.5 \mathrm{~W} / \mathrm{m} \mathrm{K}^{2}$ \\
\hline
\end{tabular}

\subsubsection{Boundary Conditions}

In order to perform CFD analysis, several boundary conditions need to be applied to the geometry. Hence, boundary conditions as shown in the following Fig 6 are applied to the design [4].

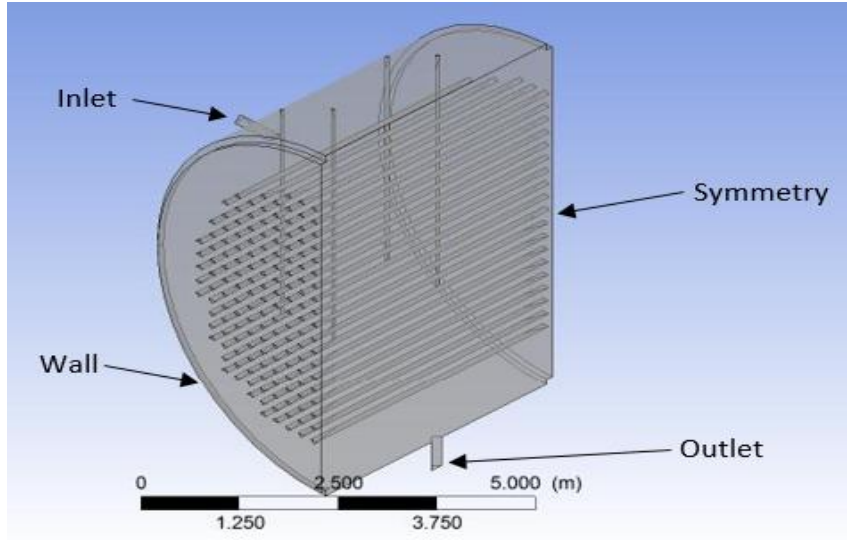

Fig6: Boundary Conditions

The values of each of the boundary conditions considered for the given design is depicted in table 5 .

\section{Table5: Boundary Conditions}

\begin{tabular}{|l|l|}
\hline $\begin{array}{l}\text { Boundary } \\
\text { Conditions }\end{array}$ & Particulars \\
\hline Inlet & $\begin{array}{l}\text { Temperature }=328 \mathrm{~K} \\
\text { Mass Flow Rate }=20 \mathrm{Kg} / \mathrm{s}\end{array}$ \\
\hline Outlet & Backflow total Temperature $=300 \mathrm{~K}$ \\
\hline $\begin{array}{l}\text { Coolant } \\
\text { Tubes }\end{array}$ & $\begin{array}{l}\text { Temperature }=341 \mathrm{~K} \\
\text { Heat Transfer Co-efficient }=7.879 \mathrm{~W} / \mathrm{m}^{2} \mathrm{~K} \\
\text { Free Steam Temperature }=300 \mathrm{~K}\end{array}$ \\
\hline
\end{tabular}

\subsection{Solution}

For the specified mass flow rate the temperature distribution in Calandria is obtained as shown in the following figures.

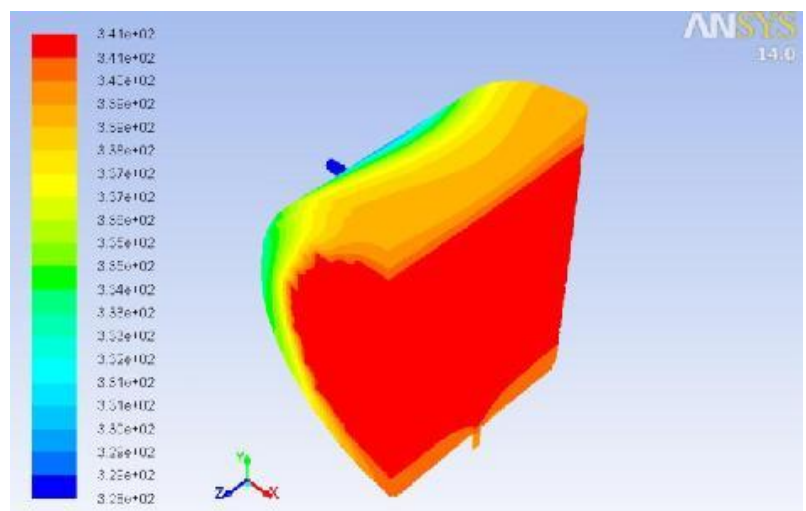

Fig7: Isometric view of temp distribution in Calandria 


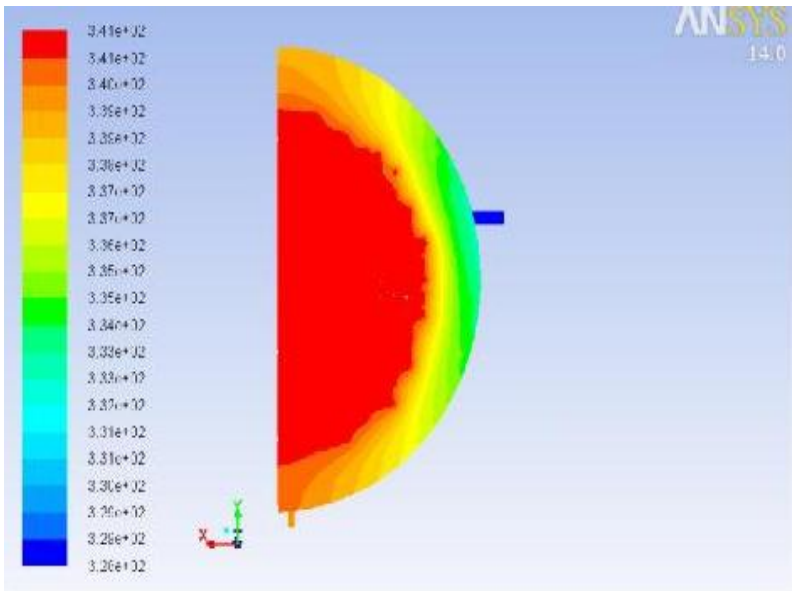

Fig8: Front view of temp distribution in Calandria

As shown in the above figures, the moderator temperature at the inlet of Calandria is found to be $328.65 \mathrm{~K}$, heat generated at the center of the Calandria, is carried by the moderator and thus, moderator temperature at the outlet of the Calandria is raised to $339.86 \mathrm{~K}$.

Inlet and outlet temperatures of moderator in the Calandria are as shown in Fig 9.

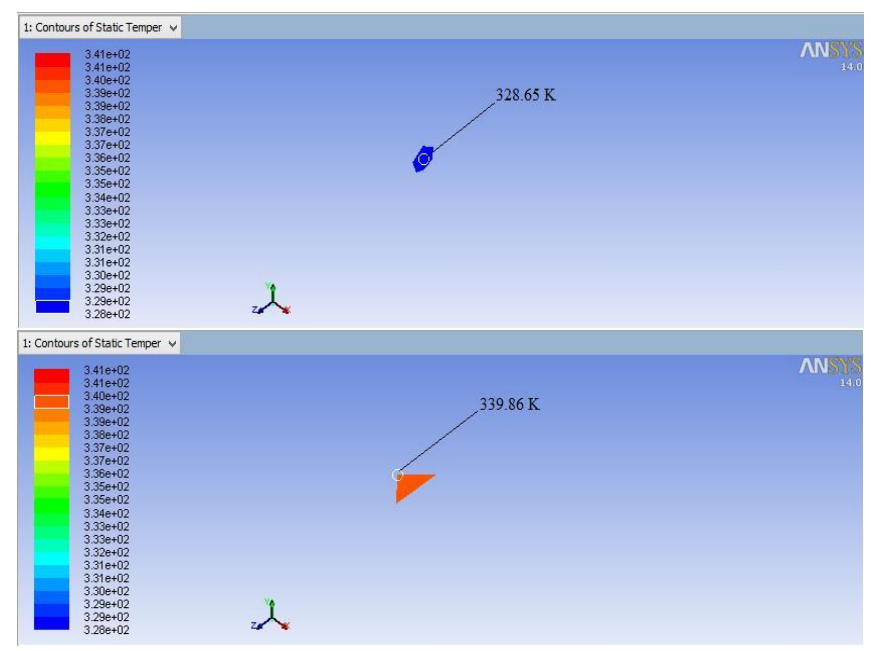

Fig9: Inlet \& outlet temperature of moderator in Calandria

\section{CONCLUSIONS}

For validation of simulated results, the simulated results are compared with actual results and found to be almost similar. The actual inlet temperature of the moderator is $328 \mathrm{~K}$ [3], whereas that obtained through simulation is $328.65 \mathrm{~K}$. Thus producing a deviation of $0.20 \%$

Likewise, actual outlet temperature of moderator is found to be $338 \mathrm{~K}$ [3], whereas that obtained through simulation is $339.86 \mathrm{~K}$. Thus producing a deviation of $0.55 \%$

Thus, it is concluded that the simulated results of the Calandria are almost identical with the actual data so obtained. Hence, proving the simulation to be considerably relevant and worth.

\section{ACKNOWLEDGEMENTS}

The authors are extremely thankful to the staff members of Mechanical Engineering Department, A. D. Patel Institute of Technology, New Vallabh Vidyanagar for providing the useful resources to carry out the simulation work. The authors are also thankful to the students of the institute for providing their untiring support \& efforts wherever needed.

\section{REFERENCES}

[1]. Shashikanth M., Ravi S. D. \& Rajan N.K.S. " $C F D$ analysis of Fluid flow and Heat Transfer in a Calandria Based Reactor validated with experimental results", Visveshwaraya Technological University, Belgaum.

[2]. Arsene R., Prisecaru I. \& Nicoloci S. "Improvement of the Thermal hydraulic characteristics in the Calandria Vessel of a CANDU 6 Nuclear Reactor", U.P.B.Sci.Bull., Series C, Vol.75, Iss.4, 2013.

[3]. Bajaj S. S. \& Gore A.R, “The Indian PHWR”, Nuclear Engineering and Design 236 (2006) 701-722.

[4]. Sarchami A., Ashgriz N. \& Kwee M., "Three dimensional numerical simulation of a full scale CANDU reactor moderator to study temperature fluctuations", Nuclear Engineering and Design 266 (2014) 148-154.

[5]. Yoon C., Rhee B. W.\& Min B. J., "3-D CFD Analysis of the CANDU-6 Moderator CIrculation under Normal Operating Conditions", Journal of the Korean Nuclear Society, Dec 2004, Volume 36, No 6, pp.559-570.

\section{BIOGRAPHIES}

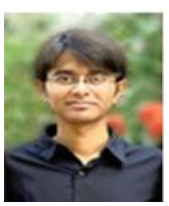

Hardik P. Patel is a final year student of Mechanical Engineering Department of A. D. Patel Institute of Technology, New V. V. Nagar.

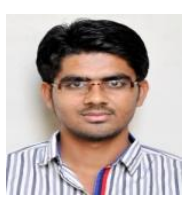

Gaurav K. Patel is a final year student of Mechanical Engineering Department of A. D. Patel Institute of Technology, New V. V. Nagar.

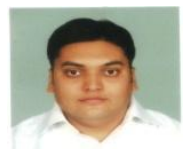

Gaurav V. Patel accomplished his postgraduation with specialization in CAD/CAM and having more than 6 years of teaching experience. He has presented/published number of papers in international \& national conferences \& Journals in the areas of CFD.

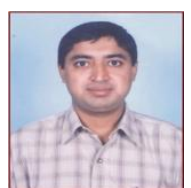

Dr. N. K. Chavda has completed his M. E. (Mech) from SVNIT, Surat and Ph. D. from The M. S. University of Baroda. He has 19 years of teaching experience and published many papers in International Journals/Conference. He has been awarded with Best Polytechnic Teacher by ISTE. 